\title{
Pediatric interfacility transport effects on mortality and length of stay
}

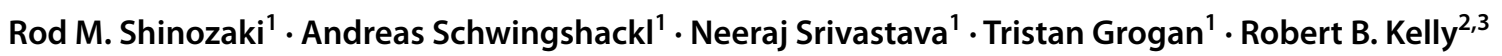

Received: 10 May 2021 / Accepted: 13 July 2021 / Published online: 28 July 2021

(c) The Author(s) 2021

\begin{abstract}
Background We aimed to evaluate the effects of interfacility pediatric critical care transport response time, physician presence during transport, and mode of transport on mortality and length of stay (LOS) among pediatric patients. We hypothesized that a shorter response time and helicopter transports, but not physician presence, are associated with lower mortality and a shorter LOS.

Methods Retrospective, single-center, cohort study of 841 patients ( $<19$ years) transported to a quaternary pediatric intensive care unit and cardiovascular intensive care unit between 2014 and 2018 utilizing patient charts and transport records. Multivariate linear and logistic regression analyses adjusted for age, diagnosis, mode of transport, response time, stabilization time, return duration, mortality risk (pediatric index of mortality-2 and pediatric risk of mortality-3), and inotrope, vasopressor, or mechanical ventilation presence on admission.

Results Four hundred and twenty-eight (50.9\%) patients were transported by helicopter, and 413 (49.1\%) were transported by ambulance. Physicians accompanied 239 (28.4\%) transports. The median response time was 2.0 (interquartile range 1.4-2.9) hours. Although physician presence increased the median response time by 0.26 hours $(P=0.020)$, neither physician presence nor response time significantly affected mortality, ICU length of stay (ILOS) or hospital length of stay (HLOS). Helicopter transports were not significantly associated with mortality or ILOS, but were associated with a longer HLOS (3.24 days, 95\% confidence interval 0.59-5.90) than ambulance transports $(P=0.017)$.

Conclusions These results suggest response time and physician presence do not significantly affect mortality or LOS. This may reflect the quality of pre-transport care and medical control communication. Helicopter transports were only associated with a longer HLOS. Our analysis provides a framework for examining transport workforce needs and associated costs.
\end{abstract}

Keywords Helicopter $\cdot$ Hospital length of stay $\cdot$ Pediatric critical care $\cdot$ Pediatric intensive care unit $\cdot$ Transport medicine

\section{Introduction}

Currently, no evidence-based pediatric guidelines exist that define the requirement for physician presence on interfacility transports, the ideal mode of transportation, or limitations of mobilization and travel times to and from outside facilities due, in part, to the paucity of studies in this field [1-4]. However, several reports suggest that the outcomes of children improve when they are transported by specialty

Robert B. Kelly

rkelly@choc.org

1 David Geffen School of Medicine at UCLA, Los Angeles, CA, USA

2 University of California, Irvine, Irvine, CA, USA

3 Children's Hospital of Orange County, 1201 West La Veta Avenue, Orange, CA 92868, USA pediatric transport teams rather than basic emergency medical services [5-7], as evidenced by improved mortality rates and decreased frequency of adverse events during transport [6, 8-10]. Non-physician transport team members have shown strong potential in providing procedural interventions, such as high successful intubation rates of 95-100\% $[11,12]$. One study comparing respiratory therapists to resident physicians on a transport team showed higher success rates for endotracheal intubation among respiratory therapists (92\% vs. 77\%) [13]. To date, only one study has compared specialty pediatric transport teams with and without a physician, and no differences in mortality were seen when adjusted for the severity of illness of the transported patients [12].

Furthermore, when comparing air versus ground transports, studies have suggested that helicopters are faster at transporting patients than ambulances [14] and are associated with improved survival in adult [15] and pediatric trauma patients [16-18]. 
Only one adult study showed that transport time intervals are independently associated with intensive care unit (ICU) length of stay (ILOS) and hospital length of stay (HLOS) [19], and one neonatal study on premature infants showed that faster response times were not associated with improved outcomes [20].

Our aim was to investigate whether an association exists between (1) interfacility response time; (2) mode of transport; and (3) physician presence during the transport of critically ill children and clinically relevant outcomes, including (1) mortality; (2) ILOS; and (3) HLOS. We hypothesized that a shorter response time and helicopter transports, but not physician presence, are associated with lower mortality and a shorter LOS after adjusting for relevant risk factors.

\section{Methods}

\section{Setting}

The UCLA Mattel Children's Hospital pediatric ICU (PICU) is a 24-bed quaternary unit affiliated with the University of California, Los Angeles, which also cares for post-operative cardiovascular surgical patients. Our pediatric critical care transport (PCCT) team includes, at a minimum, a respiratory therapist and a pediatric critical care nurse. Only if the PICU team deems it necessary given the patient's perceived clinical condition will the on-call (home or in-house) physician be activated. The physician team includes PICU and neonatal ICU (NICU) attendings, pediatric critical care and neonatal-perinatal medicine fellows, and emergency medicine resident physicians. Respiratory therapists are required to have a number of competencies within the adult ICU, PICU, NICU, and emergency department. All members complete air flight safety classes and equipment workshops. Our PCCT team nurses are highly trained with a minimum of 3 years of experience as bedside PICU and/or NICU nurses before being trained to go on transports. PCCT team physicians are not required to be on site at all times, but available within 30 minutes. The PCCT team's intake area extends throughout California and Nevada, but most transported patients are within a heavily trafficked metropolitan region. Each year the PCCT team performs an average of over 350 pediatric and neonatal critical care transports by ground and air. REACH Air Medical Services (Santa Rosa, CA) is the preferred helicopter provider for UCLA Mattel Children's Hospital, but our own UCLA PCCT team members accompany REACH crewmembers as the primary care providers.

\section{Data collection}

The UCLA Institutional Review Board approved this study and waived informed consent. A chart review of all PCCTs between January 2014 and August 2018 was performed. A patient met inclusion criteria if they were transported by our PCCT team to the PICU at UCLA and were 18 years of age or younger. Exclusion criteria included patients who were not transported to the PICU at UCLA, were transported by fixedwing aircraft, were patients greater than 18 years of age, or were intra-facility transports. Original data variables of age, diagnosis, mode of transport, physician presence during transport, and transport team departure time were obtained from the UCLA Mattel Children's Hospital's transport database. These data elements are entered by the critical care transport nurse after each transport. We defined the following transport time intervals as: mobilization time $=$ time from referral call to team departure; travel duration=time from accepting hospital to the referring hospital; response time $=$ mobilization time + travel duration; stabilization time = time spent preparing the patient to leave; return transport time=time spent traveling back (Fig. 1). Through UCLA's Clinical and Translational Science Institute's informatics program, we reviewed each patient's electronic health record to extract information
Fig. 1 Depiction of a typical interfacility transport and associated time intervals. PICU pediatric intensive care unit

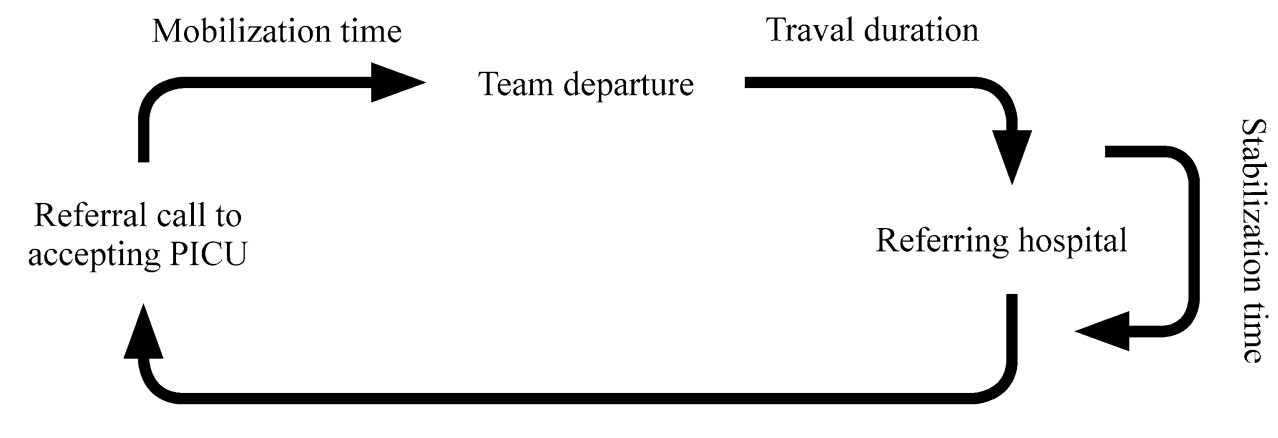

Team departure

Traval duration

Return transport time

Response time
Referral call to accepting PICU
Referring hospital 
on inotrope, vasopressor, and mechanical ventilation requirements on admission. Registry Partners (Burlington, NC), an independent data extraction group contracted with UCLA, provided pediatric index of mortality-2 (PIM-2) [21], pediatric risk of mortality-3 (PRISM-3) [22], and PRISM-3 probability of death (POD) [23] scores for each transported patient admitted to the PICU. To provide consistency, a single investigator (RMS) coordinated or performed all data abstraction.

\section{Statistical methods}

Patient characteristics and study variables were summarized using the medians [interquartile range (IQR)] for continuous variables or frequency $(\%)$ for categorical variables. We compared patient, transport, and outcome variables between physician presence and mode of transportation using the Chi-square test or Student's $t$ test, as appropriate. Finally, to determine if physician presence, response time, or air transport were associated with our predefined study outcomes (mortality, ILOS, and HLOS) after adjusting for patient morbidity (PIM-2 and PRISM-3 scores) and other patient characteristics, we ran multivariable logistic or linear regression models. To assess outcomes (mortality, ILOS, and HLOS) between diagnostic categories, we used trauma patients as the referent category, since this group was moderately sized and had the lowest LOS of all 10 diagnostic groups. We ran complete case analyses for these models, and seven patients were excluded due to missing stabilization and/or return times. These seven patients did not appear characteristically different than the other patients, therefore the assumption of these to be missing completely at random seemed reasonable, and we proceeded with the analyses. From the models, we extracted the relevant odds ratios with $95 \%$ confidence intervals (CIs) or effect sizes with $95 \%$ CIs. A propensity score modeling approach was also run as a sensitivity analysis for physician presence and air versus ground transports. Statistical analyses were performed using SPSS V25 (IBM Corp., Armonk, NY) or R V3.5.1 (www.r-project.org, Vienna, Austria). $P$ values $<0.05$ were considered statistically significant. Standard mortality ratios (SMR) were calculated by observed mortality within our ICU divided by expected mortality from PRISM-3 POD.

\section{Results}

Between January 2014 and August 2018, 1508 pediatric patients were transported to UCLA by our PCCT team. After excluding 556 patients due to non-PICU transports, fixed-wing transports, transports of patients greater than 18 years of age, and intra-facility transports, 952 patients

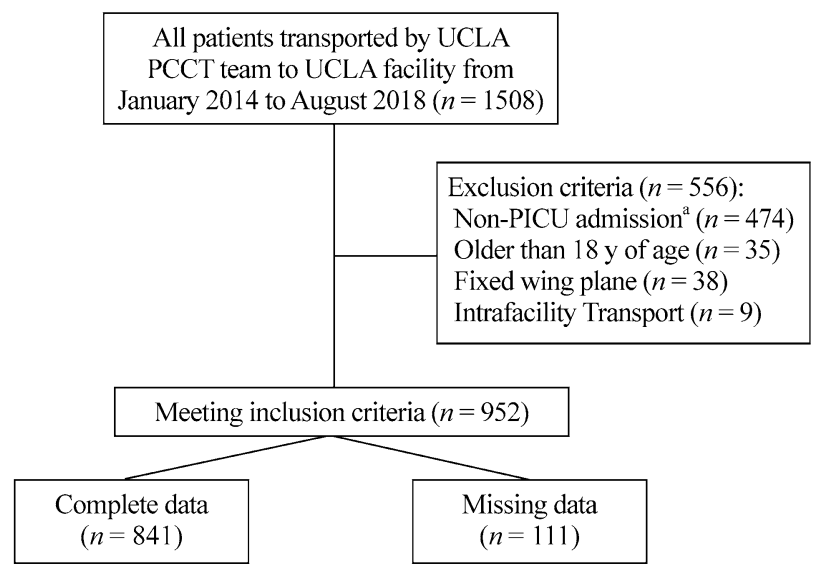

Fig. 2 Depiction of study population analyzed. PCCT pediatric critical care transport, $P I C U$ pediatric intensive care unit, $N I C U$ neonatal intensive care unit. ${ }^{a} \mathrm{NICU}$, inpatient wards, step-down off-site PICU, emergency room

met inclusion criteria. However, due to missing data points, ultimately 841 patient transports were analyzed (Fig. 2). The median age of the transported PICU patients was 4.91 (IQR 0.99-12.96) years. The most common diagnoses were categorized as respiratory $(252,30.0 \%)$, neurological $(224,26.6 \%)$, and cardiovascular $(99,11.8 \%)$. The median PIM-2 score was -4.56 (IQR -4.83 to 3.33 ), and the median PRISM-3 score was 2 (IQR 0-6). On admission, 159 (18.9\%) patients were receiving inotrope or vasopressor infusions, and 174 (20.7\%) patients were mechanically ventilated. Helicopter transports were utilized for 428 (50.9\%) patients, and ambulance transports were utilized for 413 (49.1\%). Physicians were present on 239 (28.4\%) transports. The median response time was 2.0 (IQR 1.4-2.9) hours, and the median stabilization time was 0.67 (IQR $0.45-0.97$ ) hours. The allcause mortality rate during the first 48 hours after admission was $1.5 \%$ (13 patients) and 6.4\% (54 patients) during hospitalization. The overall SMR was 1.64. If a physician was present on the transport, the SMR was 1.60 , compared to 1.73 when a physician was not present $(P=0.812)$. The SMR for helicopter transports was 1.77 compared to 1.44 for ground transports $(P=0.369)$. The median ILOS was 2.7 (IQR 1.4-7.0) days, and the median HLOS was 5.0 (IQR 2.0-13.3) days (Table 1).

Univariate analysis revealed that physician presence and helicopter transports were both significantly associated with worse PIM-2 and PRISM-3 scores (Tables 2 and 3 ). The median response time when physicians were present was 2.18 hours compared to 1.92 hours when no physician was present, resulting in a difference of 0.26 hours $(P=0.020)$. However, physician presence and response time were not significantly associated with our outcomes of interest (mortality, ILOS and HLOS) when adjusting for age, diagnosis, mode of transport, response 
Table 1 Summary of demographics and outcomes $(n=841)$

\begin{tabular}{|c|c|}
\hline Patient characteristics & Values \\
\hline Median age (y), median (IQR) & $4.91(0.99-12.96)$ \\
\hline \multicolumn{2}{|l|}{ Diagnosis, $n(\%)$} \\
\hline Respiratory & $252(30.0)$ \\
\hline Neurologic & $224(26.6)$ \\
\hline Cardiovascular & $99(11.8)$ \\
\hline Sepsis & $61(7.3)$ \\
\hline Gastrointestinal & $49(5.8)$ \\
\hline Trauma & $46(5.5)$ \\
\hline Metabolic & $44(5.2)$ \\
\hline Other & $27(3.2)$ \\
\hline Hematology/oncology & $21(2.5)$ \\
\hline Renal & $18(2.1)$ \\
\hline Median PIM-2, median (IQR) & $-4.56(-4.83$ to -3.33$)$ \\
\hline Median PRISM-3, median (IQR) & $2(0-6)$ \\
\hline Median PRISM-3 POD, median (IQR) & $0.51(0.30-1.30)$ \\
\hline Inotrope/vasopressor drip on admission, $n(\%)$ & $159(18.9)$ \\
\hline Ventilated on admission, $n(\%)$ & $174(20.7)$ \\
\hline \multicolumn{2}{|l|}{ Transport characteristics } \\
\hline Helicopter (vs. ground), $n(\%)$ & $428(50.9)$ \\
\hline Emergent transport (vs. urgent), $n(\%)$ & $308(36.6)$ \\
\hline Physician present, $n(\%)$ & $239(28.4)$ \\
\hline Median mobilization time (h), median (IQR) & $1.33(0.88-1.98)$ \\
\hline Median stabilization time (h), median (IQR) & $0.67(0.45-0.97)$ \\
\hline Median return time (h), median (IQR) & $0.58(0.35-0.88)$ \\
\hline Median stabilization + return time (h), median (IQR) & $1.33(0.99-1.83)$ \\
\hline Median response time (h), median (IQR) & $2.0(1.4-2.9)$ \\
\hline \multicolumn{2}{|l|}{ Outcomes } \\
\hline Mortality (within $48 \mathrm{~h}$ of hospital admission), $n(\%)$ & $13(1.5)$ \\
\hline Mortality (during hospital admission), $n(\%)$ & $54(6.4)$ \\
\hline Median hospital LOS (d), median (IQR) & $5.0(2.0-13.3)$ \\
\hline Median ICU LOS (d), median (IQR) & $2.7(1.4-7.0)$ \\
\hline
\end{tabular}

Due to some missing time interval data, time intervals are not additive. PIM-2 pediatric index of mortality-2, PRISM-3 pediatric risk of mortality-3, $P O D$ probability of death, $L O S$ length of stay, ICU intensive care unit, IQR 25-75th interquartile range

time, stabilization time, return duration, mortality risk (PIM-2 and PRISM-3), and inotrope, vasopressor or mechanical ventilation presence on admission (Table 4). Compared to ground transports, helicopter transports resulted in an average increase in HLOS of 3.24 (95\% CI $0.59-5.90 ; P=0.017$ ) days, but not in ILOS (average 1.68 days; $95 \% \mathrm{CI}-0.11$ to $3.47 ; P=0.066$ ). As a sensitivity analysis, we elected to perform a propensity score matched analysis with the same variables to confirm our multivariable model estimates for both the effect of physician presence and helicopter transports on our three outcomes of interest (mortality, ILOS, and HLOS). In general, the multivariable and propensity score models produced similar estimates and $P$ values (results not shown).

\section{Discussion}

Our analysis of 841 pediatric patients revealed that neither physician presence nor response time was significantly associated with mortality, ILOS, or HLOS. We did find that helicopter transports were not significantly associated with mortality or ILOS, but were associated with a longer HLOS. In our retrospective cohort study, we used data from our PCCT team database and electronic medical record to study transport characteristics among a critically ill pediatric patient population with a diverse set of diagnoses. This is the first study to comprehensively investigate the effects of transport team response time, physician presence during transport, and mode of transportation on mortality and LOS among a critically ill pediatric cohort. 
Table 2 Comparison between physician presence and patient characteristics

\begin{tabular}{|c|c|c|c|}
\hline \multirow[t]{2}{*}{ Patient characteristics } & \multicolumn{3}{|l|}{ Physician presence } \\
\hline & No $(n=602)$ & Yes $(n=239)$ & $P$ \\
\hline Median age (y), median (IQR) & $5.44(1.18-13.13)$ & $3.07(0.59-12.07)$ & 0.030 \\
\hline Diagnosis, $n(\%)$ & & & $<0.001$ \\
\hline Respiratory & $164(27.2)$ & $88(36.8)$ & \\
\hline Neurologic & $183(30.4)$ & $41(17.2)$ & \\
\hline Cardiovascular & $48(8.0)$ & $51(21.3)$ & \\
\hline Sepsis & $43(7.1)$ & $18(7.5)$ & \\
\hline Gastrointestinal & $36(6.0)$ & $13(5.4)$ & \\
\hline Trauma & $36(6.0)$ & $10(4.2)$ & \\
\hline Metabolic & $38(6.3)$ & $6(2.5)$ & \\
\hline Other & $20(3.3)$ & $7(2.9)$ & \\
\hline Hematology/oncology & $17(2.8)$ & $4(1.7)$ & \\
\hline Renal & $17(2.8)$ & $1(0.4)$ & \\
\hline Median PIM-2, median (IQR) & $-4.63(-4.86$ to -4.28$)$ & $-3.41(-4.61$ to -2.74$)$ & $<0.001$ \\
\hline Median PRISM-3, median (IQR) & $0.00(0.00-4.00)$ & $5.00(0.00-10.00)$ & $<0.001$ \\
\hline Median PRISM-3 POD, median (IQR) & $0.49(0.30-0.90)$ & $1.05(0.51-3.91)$ & $<0.001$ \\
\hline Inotrope/vasopressor drip on admission, $n(\%)$ & $64(10.6)$ & $95(39.7)$ & $<0.001$ \\
\hline Ventilated on admission, $n(\%)$ & $45(7.5)$ & $129(54.0)$ & $<0.001$ \\
\hline \multicolumn{4}{|l|}{ Transport characteristics } \\
\hline Helicopter (vs. ground), $n(\%)$ & $271(45.0)$ & $157(65.7)$ & $<0.001$ \\
\hline Emergent transport (vs. urgent), $n(\%)$ & $178(29.6)$ & $130(54.4)$ & $<0.001$ \\
\hline Physician present, $n(\%)$ & $0(0)$ & $239(100)$ & - \\
\hline Median mobilization time (h), median (IQR) & $1.23(0.80-1.88)$ & $1.47(1.08-2.28)$ & $<0.001$ \\
\hline Median stabilization time (h), median (IQR) & $0.58(0.42-0.80)$ & $1.00(0.75-1.42)$ & $<0.001$ \\
\hline Median return time (h), median (IQR) & $0.53(0.33-0.83)$ & $0.63(0.40-1.00)$ & 0.023 \\
\hline Median stabilization + return time (h), median (IQR) & $1.17(0.92-1.57)$ & $1.73(1.30-2.27)$ & $<0.001$ \\
\hline Median response time (h), median (IQR) & $1.92(1.26-2.78)$ & $2.18(1.58-3.25)$ & 0.020 \\
\hline \multicolumn{4}{|l|}{ Outcomes } \\
\hline Mortality (within $48 \mathrm{~h}$ of hospital admission), $n(\%)$ & $4(0.7)$ & $9(3.8)$ & 0.001 \\
\hline Mortality (during hospital admission), $n(\%)$ & $20(3.3)$ & $34(14.2)$ & $<0.001$ \\
\hline Median hospital LOS (d), median (IQR) & $4.25(1.75-9.64)$ & $9.57(3.42-22.10)$ & $<0.001$ \\
\hline Median ICU LOS (d), median (IQR) & $2.00(1.13-4.76)$ & $6.76(2.40-17.29)$ & $<0.001$ \\
\hline
\end{tabular}

Due to some missing time interval data, time intervals are not additive. PIM-2 pediatric index of mortality-2, PRISM-3 pediatric risk of mortality-3, $P O D$ probability of death, $L O S$ length of stay, ICU intensive care unit, $I Q R 25-75$ th interquartile range. "-" none

Our mortality results are consistent with a study by Sharpe et al. [20] who also found no difference in mortality when adjusting for response time, but this study only analyzed 105 infants less than 29 weeks gestation. Belway et al. [19] found that mortality among adult cardiac patients was not associated with various transport time intervals, but longer response times were associated with a shorter HLOS. The authors speculated that their findings were due to the referring hospital's ability to stabilize patients before being transported to the specialized unit. These findings are consistent with data from UC Davis Children's Hospital showing the quality of pre-transport clinical care and close communication with the outside hospital before the PCCT team's arrival can help improve illness severity scores on admission [24]. We speculate that the effects of prolonged transport times can be mitigated by continued improvements in prehospital care and practice guideline development as well as close communication between accepting and referring hospitals. Some patients, however, may simply need expeditious transport to an accepting hospital for definitive care despite stabilization attempts at a referring hospital or close communication between the referring hospital and the accepting hospital. Given the heterogeneity of our patient cohort in terms of diagnoses, we speculated that certain diagnoses, such as trauma, may be more sensitive to prolonged transport times. To investigate these 
Table 3 Comparison between mode of transport and patient characteristics

\begin{tabular}{|c|c|c|c|}
\hline \multirow[t]{2}{*}{ Patient characteristics } & \multicolumn{3}{|l|}{ Mode of transport } \\
\hline & Ground $(n=413)$ & Air $(n=428)$ & $P$ \\
\hline Median age (y), median (IQR) & $5.86(1.22-13.46)$ & $3.91(0.67-12.43)$ & 0.034 \\
\hline Diagnosis, $n(\%)$ & & & 0.057 \\
\hline Respiratory & $121(29.3)$ & $131(30.6)$ & \\
\hline Neurologic & $113(27.4)$ & $111(25.9)$ & \\
\hline Cardiovascular & $41(9.9)$ & $58(13.6)$ & \\
\hline Sepsis & $33(8.0)$ & $28(6.5)$ & \\
\hline Gastrointestinal & $21(5.1)$ & $28(6.5)$ & \\
\hline Trauma & $19(4.6)$ & $27(6.3)$ & \\
\hline Metabolic & $22(5.3)$ & $22(5.1)$ & \\
\hline Other & $19(4.6)$ & $8(1.9)$ & \\
\hline Hematology/oncology & $16(3.9)$ & $5(1.2)$ & \\
\hline Renal & $8(1.9)$ & $10(2.3)$ & \\
\hline Median PIM-2, median (IQR) & $-4.58(-4.83$ to -3.53$)$ & $-4.55(-4.83$ to -3.17$)$ & 0.007 \\
\hline Median PRISM-3, median (IQR) & $2.00(0.00-5.00)$ & $3.00(0.00-7.00)$ & 0.014 \\
\hline Median PRISM-3 POD, median (IQR) & $0.51(0.30-1.08)$ & $0.63(0.30-1.79)$ & 0.135 \\
\hline Inotrope/vasopressor drip on admission, $n(\%)$ & $63(15.3)$ & $96(22.4)$ & 0.008 \\
\hline Ventilated on admission, $n(\%)$ & $65(15.7)$ & $109(25.5)$ & $<0.001$ \\
\hline \multicolumn{4}{|l|}{ Transport characteristics } \\
\hline Helicopter (vs. ground), $n(\%)$ & $0(0)$ & $428(100)$ & - \\
\hline Emergent transport (vs. urgent), $n(\%)$ & $174(42.1)$ & $134(31.3)$ & 0.001 \\
\hline Physician present, $n(\%)$ & $82(19.9)$ & $157(36.7)$ & $<0.001$ \\
\hline Median mobilization time (h), median (IQR) & $0.99(0.63-1.58)$ & $1.55(1.17-2.23)$ & 0.005 \\
\hline Median stabilization time (h), median (IQR) & $0.52(0.37-0.75)$ & $0.80(0.58-1.15)$ & $<0.001$ \\
\hline Median return time (h), median (IQR) & $0.50(0.33-0.75)$ & $0.63(0.42-1.00)$ & 0.268 \\
\hline Median stabilization + return time $(\mathrm{h})$, median (IQR) & $1.08(0.83-1.53)$ & $1.50(1.17-2.03)$ & $<0.001$ \\
\hline Median response time (h), median (IQR) & $1.65(0.98-2.65)$ & $2.20(1.72-3.03)$ & 0.456 \\
\hline \multicolumn{4}{|l|}{ Outcomes } \\
\hline Mortality (within $48 \mathrm{~h}$ of hospital admission), $n(\%)$ & $5(1.2)$ & $8(1.9)$ & 0.439 \\
\hline Mortality (during hospital admission), $n(\%)$ & $19(4.6)$ & $35(8.2)$ & 0.034 \\
\hline Median hospital LOS (d), median (IQR) & $4.51(1.76-10.83)$ & $5.40(2.43-15.51)$ & 0.001 \\
\hline Median ICU LOS (d), median (IQR) & $2.40(1.24-5.78)$ & $2.97(1.51-9.45)$ & 0.001 \\
\hline
\end{tabular}

Due to some missing time interval data, time intervals are not additive. PIM-2 pediatric index of mortality-2, PRISM-3 pediatric risk of mortality-3, $P O D$ probability of death, $L O S$ length of stay, ICU intensive care unit, IQR 25-75th interquartile range. “-” none

potential outcome differences between patient subgroups, we attempted a subgroup analysis based on diagnosis, but we could not achieve adequate power.

Herrup et al. [25] surveyed several transport programs and revealed substantial heterogeneity in the subspecialty training level of transport physicians (PICU fellows, neonatology fellows, pediatric emergency fellows, or pediatric anesthesiology fellows) and the years of experience and requirements before joining the team. A survey among transport team members by McCloskey et al. [26] concluded that $46 \%$ of respondents felt that a physician was needed to transport critically ill patients. A registry is likely required to track team composition and level of training along with outcomes before any broad conclusions can be made beyond our center. The high level of competency of our PCCT team nurse and respiratory therapist may be the reason for the lack of effect of physician presence on transport. Similar to the physician's level of training, a formal analysis of the competency of all other transport team members may reveal strategies to further improve safety, outcomes, and cost of high acuity pediatric transports.

Our study did not show a lower mortality or reduced ILOS with helicopter transports. We suspect that pretransport stabilization, small diagnostic sample sizes, and an overall shorter total transport time relative to a patient's overall ILOS likely explain these findings. Delgado et al. 
Table 4 Multivariate analyses of the association between transport variables and outcomes

\begin{tabular}{|c|c|c|c|c|c|c|}
\hline \multirow[t]{2}{*}{ Outcomes } & \multicolumn{2}{|c|}{ Mortality during admission } & \multicolumn{2}{|l|}{ Hospital LOS (d) } & \multicolumn{2}{|l|}{ ICU LOS (d) } \\
\hline & OR $(95 \% \mathrm{CI})$ & $P$ & Effect (95\% CI) & $P$ & Effect $(95 \%$ CI $)$ & $P$ \\
\hline Age (y) & 0.97 (0.91 to 1.03$)$ & 0.269 & $-0.09(-0.31$ to 0.13$)$ & 0.427 & $-0.14(-0.29$ to 0.01$)$ & 0.063 \\
\hline Diagnosis & & 0.185 & & 0.001 & & 0.004 \\
\hline Respiratory & $1.05(0.13$ to 8.41$)$ & 0.967 & $6.36(0.27$ to 12.45$)$ & 0.041 & $4.58(0.46$ to 8.69$)$ & 0.029 \\
\hline Neurologic & $0.19(0.02$ to 2.27$)$ & 0.190 & $3.39(-2.55$ to 9.34$)$ & 0.263 & $1.01(-3.01$ to 5.02$)$ & 0.623 \\
\hline Cardiovascular & $1.42(0.17$ to 11.50$)$ & 0.744 & $10.00(3.19$ to 16.81$)$ & 0.004 & 7.70 (3.10 to 12.30$)$ & 0.001 \\
\hline Sepsis & $2.04(0.24$ to 17.33$)$ & 0.513 & $11.86(4.53$ to 19.18$)$ & 0.002 & $5.14(0.20$ to 10.08$)$ & 0.041 \\
\hline Gastrointestinal & $0.64(0.06$ to 6.79$)$ & 0.713 & $9.06(1.53$ to 16.60$)$ & 0.018 & $3.20(-1.89$ to 8.28$)$ & 0.217 \\
\hline Metabolic & $0.61(0.03$ to 10.84$)$ & 0.733 & $6.63(-1.42$ to 14.68$)$ & 0.106 & $2.50(-2.93$ to 7.94$)$ & 0.366 \\
\hline Other & 1.09 (0.04 to 28.87$)$ & 0.959 & $3.44(-6.19$ to 13.07$)$ & 0.483 & $1.31(-5.19$ to 7.81$)$ & 0.693 \\
\hline Hematology/oncology & $4.70(0.46$ to 48.42$)$ & 0.193 & 18.20 (8.49 to 27.92$)$ & $<0.001$ & $4.46(-2.09$ to 11.02$)$ & 0.182 \\
\hline Renal & $0.00(0.00$ to 999$)$ & 0.998 & $12.30(2.22$ to 22.38$)$ & 0.017 & $5.54(-1.26$ to 12.35$)$ & 0.110 \\
\hline PIM-2 & 2.00 (1.40 to 2.86$)$ & $<0.001$ & $0.33(-1.05$ to 1.71$)$ & 0.635 & $0.13(-0.80$ to 1.06$)$ & 0.784 \\
\hline PRISM-3 & 1.10 (1.03 to 1.17$)$ & 0.002 & $-0.17(-0.46$ to 0.11$)$ & 0.224 & $-0.09(-0.28$ to 0.10$)$ & 0.376 \\
\hline $\begin{array}{l}\text { Inotrope or vasopressor on } \\
\text { admission }\end{array}$ & 1.04 (0.36 to 3.02$)$ & 0.936 & 7.17 (2.91 to 11.44$)$ & 0.001 & $5.70(2.81$ to 8.58$)$ & $<0.001$ \\
\hline Ventilated on admission & $0.96(0.32$ to 2.91$)$ & 0.946 & $4.29(-0.06$ to 8.64$)$ & 0.053 & 4.49 (1.55 to 7.42$)$ & 0.003 \\
\hline Emergent transport & $1.19(0.50$ to 2.85$)$ & 0.697 & $0.80(-2.02$ to 3.62$)$ & 0.577 & $0.81(-1.10$ to 2.71$)$ & 0.407 \\
\hline Helicopter transport & $1.67(0.71$ to 3.90$)$ & 0.236 & $3.24(0.59$ to 5.90$)$ & 0.017 & $1.68(-0.11$ to 3.47$)$ & 0.066 \\
\hline Physician presence & $0.86(0.31$ to 2.38$)$ & 0.777 & $3.17(-0.39$ to 6.73$)$ & 0.081 & $1.68(-0.72$ to 4.08$)$ & 0.171 \\
\hline Response time & $0.97(0.84$ to 1.11$)$ & 0.618 & $0.15(-0.27$ to 0.57$)$ & 0.486 & $-0.02(-0.31$ to 0.26$)$ & 0.880 \\
\hline Stabilization time & $0.98(0.76$ to 1.27$)$ & 0.889 & $0.62(-0.76$ to 2.00$)$ & 0.376 & $0.49(-0.44$ to 1.43$)$ & 0.300 \\
\hline Return time & $0.93(0.57$ to 1.51$)$ & 0.770 & $1.13(-0.15$ to 2.42$)$ & 0.083 & $0.58(-0.29$ to 1.44$)$ & 0.191 \\
\hline
\end{tabular}

Due to some missing time interval data, time intervals are not additive. $P$ values with bold letters indicating significance. $P I M-2$ pediatric index of mortality-2, PRISM-3 pediatric risk of mortality-3, LOS length of stay, ICU intensive care unit, $O R$ odds ratio, $C I$ confidence interval

[27] showed that for helicopter transports to be cost-effective they would need a relative risk reduction in mortality of $15 \%$ compared to ground transport when utilizing the costeffectiveness ratio of less than $\$ 100,000$ per quality-adjusted life-year gained. Taylor et al. [28] reviewed studies showing helicopter transport programs commonly lack cost-effectiveness. There are no widely used algorithms to determine the indicated or recommended modality of transport among PCCT teams. Transport programs deal with varying local traffic conditions, weather patterns, and team resource limitations, all of which can affect the decision-making process.

Lastly, we speculate that the significant increase in HLOS for helicopter transports compared to ground transports may be due to limitations in vital sign monitoring, altitude and vibration effects, crew resource management during flight, space limitations, and conservative discharge criteria due to potentially long distances for necessary follow-up appointments. These factors are likely minor confounders, thereby less likely to affect ILOS or mortality to the same extent. Without a larger, multi-center study, we caution against using these results to limit this expensive mode of transport among pediatric patients requiring interfacility transport.
Our study has a number of strengths. First, we utilized two standard and commonly calculated illness severity scores, PIM-2, and PRISM-3, while also adjusting for inotrope, vasopressor, and mechanical ventilation use along with various transport time intervals. Second, the heterogeneity of diagnoses and degree of disease severity among our patients allowed us to study a unique population likely to be at the highest risk during interfacility transport. Third, our high rate of helicopter transports due to our hospital's geographical location, referral base, and traffic congestion allows us to speculate on how helicopter transports can impact medical outcomes. Lastly, we applied multivariate analyses and propensity score modeling as a sensitivity analysis to demonstrate the feasibility of such a study. Conducting a randomized controlled trial evaluating physician presence, mode of transportation, and response time would be challenging and perhaps impossible to conduct ethically or with equipoise.

There are several limitations to our study. Our study may be underpowered to detect a clinically meaningful difference in mortality given that the all-cause mortality during hospitalization was $6.4 \%$. Furthermore, $11.6 \%$ of our patients were excluded due to missing data points. 
Although we attempted to account for confounders by performing multivariate logistic and linear regression analyses as well as propensity score matching, it is possible that we still missed additional confounding effects [29]. We attempted to control for illness severity utilizing PIM-2 and PRISM-3 scores, which, to our knowledge, has not been done in pediatric interfacility transport research. We recognize that PRISM-3 may be an inaccurate reflection of transport illness severity since the score is calculated from data obtained during the first 12 hours of admission. The score could, therefore, be influenced by therapies administered during that time [30]. Future studies utilizing PRISM-4 scores may be more reflective considering this score is calculated using a data range spanning from two hours before admission to four hours after admission [22].

In conclusion, our analysis of 841 pediatric patients revealed that neither physician presence nor response time was significantly associated with mortality, ILOS or HLOS. We did find that helicopter transports were not significantly associated with mortality or ILOS, but were associated with a longer HLOS. Despite the limitations of a single-center study, our analysis provides a framework for examining transport workforce needs and helps guide further studies using large PCCT databases to further characterize the impact of time intervals, mode of transport, and physician presence.

Author contributions RMS contributed to data curation, investigation, methodology, writing of original draft, review and editing. AS and NS contributed to methodology, review and editing. TG contributed to formal analysis, funding acquisition, methodology, software, review and editing. RBK contributed to conceptualization, investigation, methodology, project administration, supervision, review and editing. All the authors approved the final version of the manuscript to be published.

Funding Statistical analysis by TG was funded by NIH National Center for Advancing Translational Science (UCLA CTSI grant number: UL1TR001881). The NIH had no role in the design and conduct of the study.

\section{Compliance with ethical standards}

Ethical approval The UCLA Institutional Review Board approved this study and waived informed consent (\#18-001707).

Conflict of interest No financial or non-financial benefits have been received or will be received from any party related directly or indirectly to the subject of this article. The authors have no conflict of interest to declare.

Data availability The datasets generated during and/or analyzed during the current study are not publicly available due to individual privacy, but are available from the corresponding author upon reasonable request.
Open Access This article is licensed under a Creative Commons Attribution 4.0 International License, which permits use, sharing, adaptation, distribution and reproduction in any medium or format, as long as you give appropriate credit to the original author(s) and the source, provide a link to the Creative Commons licence, and indicate if changes were made. The images or other third party material in this article are included in the article's Creative Commons licence, unless indicated otherwise in a credit line to the material. If material is not included in the article's Creative Commons licence and your intended use is not permitted by statutory regulation or exceeds the permitted use, you will need to obtain permission directly from the copyright holder. To view a copy of this licence, visit http://creativecommons.org/licenses/by/4.0/.

\section{References}

1. Warren J, Fromm RE, Orr RA, Rotello LC, Horst HM, American College of Critical Care Medicine. Guidelines for the inter- and intrahospital transport of critically ill patients. Crit Care Med. 2004;32:256-62.

2. Rosenberg DI, Moss MM, American College of Critical Care Medicine of the Society of Critical Care Medicine. Guidelines and levels of care for pediatric intensive care units. Crit Care Med. 2004;32:2117-27.

3. Shirley PJ, Hearns S. Retrieval medicine: a review and guide for UK practitioners. Part 1: clinical guidelines and evidence base. Emerg Med J. 2006;23:937-42.

4. Hearns S, Shirley PJ. Retrieval medicine: a review and guide for UK practitioners. Part 2: safety in patient retrieval systems. Emerg Med J. 2006;23:943-7.

5. Chance GW, Matthew JD, Gash J, Williams G, Cunningham K. Neonatal transport: a controlled study of skilled assistance. Mortality and morbidity of neonates less than $1.5 \mathrm{~kg}$ birth weight. J Pediatr. 1978;93:662-6.

6. Orr RA, Felmet KA, Han Y, McCloskey KA, Dragotta MA, Bills $\mathrm{DM}$, et al. Pediatric specialized transport teams are associated with improved outcomes. Pediatrics. 2009;124:40-8.

7. Ramnarayan P, Thiru K, Parslow RC, Harrison DA, Draper ES, Rowan KM. Effect of specialist retrieval teams on outcomes in children admitted to paediatric intensive care units in England and Wales: a retrospective cohort study. Lancet. 2010;376:698-704.

8. Vos GD, Nissen AC, Nieman FHM, Meurs MMB, van Waardenburg DA, Ramsay G, et al. Comparison of interhospital pediatric intensive care transport accompanied by a referring specialist or a specialist retrieval team. Intensive Care Med. 2004;30:302-8.

9. Wiegersma JS, Droogh JM, Zijlstra JG, Fokkema J, Ligtenberg JJM. Quality of interhospital transport of the critically ill: impact of a Mobile Intensive Care Unit with a specialized retrieval team. Crit Care. 2011;15:R75.

10. Patel SC, Murphy S, Penfil S, Romeo D, Hertzog JH. Impact of interfacility transport method and specialty teams on outcomes of pediatric trauma patients. Pediatr Emerg Care. 2018;34:467-72.

11. Harrison TH, Thomas SH, Wedel SK. Success rates of pediatric intubation by a non-physician-staffed critical care transport service. Pediatr Emerg Care. 2004;20:101-7.

12. King BR, King TM, Foster RL, McCans KM. Pediatric and neonatal transport teams with and without a physician: a comparison of outcomes and interventions. Pediatr Emerg Care. 2007;23:77-82.

13. Adams K, Scott R, Perkin RM, Langga L. Comparison of intubation skills between interfacility transport team members. Pediatr Emerg Care. 2000;16:5-8.

14. Svenson JE, O'Connor JE, Lindsay MB. Is air transport faster? A comparison of air versus ground transport times for interfacility transfers in a regional referral system. Air Med J. 2006;25:170-2. 
15. Michaels D, Pham H, Puckett Y, Dissanaike S. Helicopter versus ground ambulance: review of national database for outcomes in survival in transferred trauma patients in the USA. Trauma Surg Acute Care Open. 2019;4:e000211.

16. Polites SF, Zielinski MD, Fahy AS, Wagie AE, Moir CR, Jenkins $\mathrm{DH}$, et al. Mortality following helicopter versus ground transport of injured children. Injury. 2017;48:1000-5.

17. Brown JB, Leeper CM, Sperry JL, Peitzman AB, Billiar TR, Gaines BA, et al. Helicopters and injured kids: improved survival with scene air medical transport in the pediatric trauma population. J Trauma Acute Care Surg. 2016;80:702-10.

18. Englum BR, Rialon KL, Kim J, Shapiro ML, Scarborough JE, Rice HE, et al. Current use and outcomes of helicopter transport in pediatric trauma: a review of 18,291 transports. J Pediatr Surg. 2017;52:140-4.

19. Belway D, Dodek PM, Keenan SP, Norena M, Wong H. The role of transport intervals in outcomes for critically ill patients who are transferred to referral centers. J Crit Care. 2008;23:287-94.

20. Sharpe JB, Davies MW. Does earlier arrival of the retrieval team improve short-term outcomes in outborn extremely premature infants? J Paediatr Child Health. 2018;54:1234-41.

21. Slater A, Shann F, Pearson G, Paediatric Index of Mortality (PIM) Study Group. PIM2: a revised version of the Paediatric Index of Mortality. Intensive Care Med. 2003;29:278-85.

22. Pollack MM, Holubkov R, Funai T, Dean JM, Berger JT, Wessel DL, et al. The pediatric risk of mortality score: update 2015 . Pediatr Crit Care Med. 2016;17:2-9.

23. Pollack MM, Ruttimann UE, Getson PR. Pediatric risk of mortality (PRISM) score. Crit Care Med. 1988;16:1110-6.
24. Dayal P, Hojman NM, Kissee JL, Evans J, Natale JE, Huang Y, et al. Impact of telemedicine on severity of illness and outcomes among children transferred from referring emergency departments to a children's hospital PICU. Pediatr Crit Care Med. 2016;17:516-21.

25. Herrup EA, Klein BL, Schuette J, Costabile PM, Noje C. A national survey on physician trainee participation in pediatric interfacility transport. Pediatr Crit Care Med. 2020;21:222-7.

26. McCloskey KA, King WD, Byron L. Pediatric critical care transport: is a physician always needed on the team? Ann Emerg Med. 1989;18:247-9.

27. Delgado MK, Staudenmayer KL, Wang NE, Spain DA, Weir S, Owens DK, et al. Cost-effectiveness of helicopter versus ground emergency medical services for trauma scene transport in the United States. Ann Emerg Med. 2013;62:351-364.e19.

28. Taylor CB, Stevenson M, Jan S, Middleton PM, Fitzharris M, Myburgh JA. A systematic review of the costs and benefits of helicopter emergency medical services. Injury. 2010;41:10-20.

29. Leisman DE. Ten pearls and pitfalls of propensity scores in critical care research: a guide for clinicians and researchers. Crit Care Med. 2019;47:176-85.

30. Pollack MM, Dean JM, Butler J, Holubkov R, Doctor A, Meert KL, et al. The ideal time interval for critical care severity-of-illness assessment. Pediatr Crit Care Med. 2013;14:448-53.

Publisher's Note Springer Nature remains neutral with regard to jurisdictional claims in published maps and institutional affiliations. 